\title{
Cmambu
}

\section{ПОЧЕМУ ПСИХОЛОГИ НЕ ЗНАЮТ МАТЕМАТИКУ? ВЛИЯНИЕ АКТУАЛИЗАЦИИ ПРОФЕССИОНАЛЬНЫХ СТЕРЕОТИПОВ НА РЕШЕНИЕ МАТЕМАТИЧЕСКИХ ЗАДАЧ}

\author{
О.А. ГУЛЕВИЧ ${ }^{a}$, Е.А. ОРЕЛ ${ }^{\text {a }}$, М.Б. БУРОВА ${ }^{\text {a }}$
}

${ }^{a}$ Национальньй исследовательский университет «Высшая школа экономики», 101000, Россия, Москва, ул. Мясницкая, д. 20

\section{Резюме}

Стереотипная угроза - важный фактор, оказывающий влияние на учебные и профессиональные достижения человека. Источником подобной угрозы служат стереотипы, в которых подчеркивается неспособность членов определенной социальной группы решать конкретные задачи. В данном исследовании было проанализировано влияние стереотипов, касающихся психологов («психологи не способны к математике»), на отношение студентов-психологов к курсу статистики и качество решения ими математических задач. Мы предположили, что актуализация в сознании студентов-психологов стереотипной угрозы ухудшает их отношение к курсу статистики и понижает качество решения математических задач. Однако ее влияние зависит от личностных ресурсов, которыми обладают студенты: чем выше самоэффективность и жизнестойкость человека, тем меньше он подвержен воздействию негативных стереотипов. В исследовании приняли участие 94 студента-психолога, недавно приступившие к изучению статистики. Члены одной экспериментальной группы подвергались воздействию стереотипной угрозы, а члены другой - нет. Для этого у членов первой группы актуализировали негативные стереотипы: рассказывали о том, что, по данным исследований, психологи хуже решают математические задачи, чем представители других специальностей. В то же время у членов второй группы такие стереотипы не актуализировали. После этого все респонденты заполняли методики для измерения самоэффективности и жизнестойкости, оценивали свое отношение к курсу статистики, а также решали ряд математических задач. В соответствии гипотезами результаты исследования продемонстрировали, что стереотипная угроза действительно понижает эффективность решения математических задач и ухудшает отношение к курсу статистики. Однако ее влияние опосредуется самоэффективностью и одним из компонентов жизнестойкости - вовлеченностью.

Ключевые слова: стереотипы, стереотипная угроза, отношение к статистике.

Работа выполнена при поддержке гранта РГНФ № 13-06-00680 «Почему психологи не знают математику? Влияние профессиональных стереотипов на качество университетского образования». 
Стереотипы - совокупность черт, приписываемых членам определенной социальной группы, - оказывают большое влияние на поведение человека. Психологические исследования, проведенные за два последних десятилетия, продемонстрировали наличие «стереотипной угрозы» (stereotype threat) - влияния негативных стереотипов на продуктивность учебной и профессиональной деятельности членов стереотипизированных групп (Maass, Cadinu, 2003). В частности, согласно гендерным стереотипам, женщины обладают меньшими математическими способностями, хуже играют в шахматы и хуже руководят людьми, чем мужчины. В результате девушки, которым в экспериментах прямо или косвенно напоминают об этих стереотипах, хуже выполняют математические тесты, хуже играют в шахматы и реже занимают лидерские позиции, чем участницы, работающие в нейтральных условиях.

Стереотипная угроза оказывает влияние на решение как интеллектуальных (например, выполнение математических или вербальных тестов), так и физических (например, выполнение физических упражнений), как индивидуальных, так и групповых задач. Воздействие стереотипной угрозы возникает в экспериментальных лабораториях, школах, университетах и организациях; в ходе обучения (Muzzatti, Agnoli, 2007), приема на работу (Klein et al., 2007) и спортивных турниров (Rothgerber, Wolsiefer, 2014). Жертвой влияния стереотипов становятся самые разные люди, от 5-летних детей до 70-летних стариков (Maass, Cadinu, 2003).
Первоначально исследователи полагали, что подобное влияние оказывают хорошо сформированные и стабильные стереотипы. Однако со временем выяснилось, что его могут оказать и ситуативно актуализированные представления. В современных исследованиях под стереотипной угрозой понимается любая информация, говорящая о неспособности целой группы выполнять какие-либо действия и достигать успеха в какой-либо области, поэтому при моделировании стереотипной угрозы используются прямые указания на слабые способности или некомпетентность группы. В частности, для этой цели применяются специально созданные сообщения о результатах якобы проведенных исследований или описываются примеры известных людей, соответствующих стереотипам. Поразительно, но даже такое напоминание о некомпетентности и неуспешности группы оказывает влияние на успешность ее отдельных представителей.

В большинстве случаев воздействие стереотипной угрозы изучается на материале гендерных, этнических или расовых стереотипов. Однако некоторые стереотипы, которые оказывают влияние на качество обучения и профессиональной деятельности, связаны с профессиональной специализацией. Современное психологическое образование невозможно представить без курса по математической статистике. Однако в обыденном сознании профессия психолога считается гуманитарной, а психологи - людьми, обладающими слабыми способностями к математике. Этот стереотип может быть одной из причин слабого знания статистики, 
необходимой при обработке результатов психологических исследований. Неумение пользоваться современными статистическими методами приводит к тому, что специалистыпсихологи избегают современных методов исследования, как в науке, так и в практике, что, конечно, не может не сказываться на качестве их работы. В нашем исследовании мы проанализируем воздействие стереотипной угрозы, вызванной напоминанием об этом стереотипе, на отношение к курсу статистики и качество решения математических задач.

Почему стереотипная угроза оказывает столь разрушительное воздействие на продуктивность человека? Изучение этого вопроса началось в конце 1990-х гг. Проведенные исследования позволили выделить семь основных механизмов воздействия стереотипной угрозы: от нарушения когнитивной активности до деидентификации с областью деятельности.

Первые три механизма действуют в кратковременной перспективе. Благодаря им человек плохо справляется с решением конкретной задачи в определенный момент времени. К этой группе относятся посторонние мысли, негативные эмоции и усиление самоконтроля.

- Посторонние мысли. Сталкиваясь со стереотипной угрозой, человек начинает думать о содержании стереотипа. Он ищет возможность избежать провала, уделяет основное внимание тому как, а не тому, что он делает. Эти мысли уменьшают объем рабочей памяти (Croizet et al., 2004; Maass, Cadinu, 2003; Schmader, Johns, 2003; Schmader et al., 2008; Van Loo, Rydell, 2013).
- $\quad$ Негативные эмоции. Стереотипная угроза вызывает у человека тревогу, препятствующую выполнению задания (Johns et al., 2008; Maass, Cadinu, 2003; Marx, Stapel, 2006; O'Brien, Crandall, 2003; Schmader et al., 2008). Неудачное выполнение становится источником фрустрации (Marx, Stapel, 2006) и провоцирует дополнительные негативные эмоции (Keller, Dauenheimer, 2003).

- Усиление самоконтроля. Стремясь сосредоточиться, человек пытается избавиться от лишних мыслей и подавить негативные эмоции. Поскольку самоконтроль требует когнитивных ресурсов, он негативно сказывается на выполнении задания (Johns et al., 2008; Schmader et al., 2008).

Оставшиеся четыре механизма действуют в долговременной перспективе. Они изменяют отношение человека к выполняемой деятельности - его желание и способность учиться. К ним относятся трудности в обучении, уменьшение самоэффективности, усиление мотивации избегания и деидентификация с областью деятельности.

- Сложности в обучении. Вследствие недостатка когнитивных ресурсов стереотипная угроза уменьшает способность человека к усвоению нового материала (Boucher et al., 2012; Rydell et al., 2010).

- Уменьшение самоэффективности. Трудности, возникающие при выполнении задания, снижают самоэффективность человека. Он теряет уверенность в том, что сможет выполнить поставленную перед ним задачу (Cadinu et al., 2003; Leitner et al., 2013; Maass, Cadinu, 2003), испытывает разочарование в своих способностях (Marx, Roman, 2002). 
- Усиление мотивации избегания. Стереотипная угроза актуализирует у человека мотивацию избегания (Grimm et al., 2009). Она проявляется двумя способами. Во-первых, сталкиваясь со «стереотипной угрозой», человек прикладывает меньше усилий для подготовки к заданию и становится жертвой «выученной беспомощности» (Appel et al., 2011; Stone, 2002). Во-вторых, стремясь не допустить провала, человек меньше рискует (Maass, Cadinu, 2003), отдает предпочтение защите перед нападением (Maass et al., 2008), выбирает роли, предполагающие зависимость от партнера (Davies et al., 2005).

- Деидентификация с областью деятельности. Под воздействием стереотипной угрозы человек перестает считать соответствующую область деятельности «своей», испытывает напряжение и хочет стать невидимым, когда думает о ней (Good et al., 2012; Maass, Cadinu, 2003).

Таким образом, стереотипная угроза оказывает как кратковременное, так и долговременное воздействие. В контексте данного исследования это означает, что стереотипная угроза оказывает влияние как на решение студентами-психологами текущих математических задач (кратковременная перспектива), так и на отношение к курсу статистики в целом (долговременная перспектива). Как следствие, мы предположили:

Гипотеза 1а: студенты-психологи, работающие в условиях стереотипной угрозы, будут хуже решать математические задачи, чем студентыпсихологи, не подвергающиеся воздействию стереотипной угрозы.

Гипотеза 1б: студенты-психологи, работающие в условиях стереотип- ной угрозы, продемонстрируют более негативное отношение к курсу статистики, чем студенты-психологи, не подвергающиеся воздействию стереотипной угрозы.

Какие факторы определяют силу воздействия стереотипной угрозы? Известные к настоящему времени факторы связаны с наличием у человека информации о стереотипах, типом решаемых задач и обстановкой, в которой выполняется деятельность. В то же время исследователи уделяют мало внимания индивидуальным особенностям людей, которые могут блокировать воздействие стереотипной угрозы.

В частности, немногочисленные исследования показывают, что сила ее влияния зависит от локуса контроля и чувства юмора. Стереотипная угроза оказывает большее влияние на людей с внутренним локусом контроля (Cadinu et al., 2006; Maass, Cadinu, 2003) и тех, кто относится к возникающим проблемам без юмора (Ford et al., 2004). Кроме того, некоторые исследования позволяют предположить, что влияние стереотипной угрозы определяется личностными ресурсами человека: его жизнестойкостью и самоэффективностью.

Самоэффективность определяется как представление человека о своих способностях справиться с возникающими проблемами, освоить или выполнить определенную деятельность на намеченном уровне и достичь ожидаемого результата. Самоэффективность оказывает влияние на цели, которые человек ставит перед собой, его мотивацию и приложенные усилия. В частности, люди с высокой самоэффективностью считают возникающие проблемы менее 
сложными и испытывают при их возникновении меньший стресс, лучше планируют свою деятельность, ставят перед собой более сложные цели и прикладывают больше усилий для их достижения, а также чаще объясняют свои неудачи внешними факторами, чем люди с низким уровнем самоэффективности (Гордеева, 2011). Как следствие, люди с высокой самоэффективностью достигают более высоких результатов. Склонность людей с высоким уровнем самоэффективности прикладывать больше усилий при столкновении с проблемой и объяснять неудачи внешними условиями позволяет предположить, что эта характеристика уменьшает воздействие стереотипной угрозы. В частности, мы предположили:

Гипотеза 2a: чем выше самоэффективность, тем меньше стереотипная угроза влияет на эффективность решения задач.

Гипотеза 2б: чем выше самоэффективность, тем меньше стереотипная угроза влияет на оценку деятельности.

Предыдущие исследования показали, что такое влияние оказывает частная самоэффективность (Desrichard, Kopetz, 2005). В данном исследовании мы рассмотрим воздействие общей самоэффективности.

Жизнестойкость определяется как система представлений человека о себе, мире и отношениях с ним, она препятствует возникновению внутреннего напряжения в стрессовых ситуациях, а также способствует совладанию со стрессом (Рассказова, Леонтьев, 2011; Осин, Рассказова, 2013). В структуре жизнестойкости можно выделить три сравнительно автономных компонента: вовлеченность, контроль и принятие риска (Maddi, 1987). Люди с высокой жизнестойкостью изначально оценивают происходящие события как менее стрессогенные, ведут более здоровый образ жизни, а при возникновении стресса чаще используют стратегии активного совладания и чаще обращаются за социальной поддержкой, чем люди с низкой жизнестойкостью (Maddi, 1998; Maddi et al., 1998). Как следствие, люди с высоким уровнем жизнестойкости, попадая в стрессовые ситуации, сохраняют здоровье, высокий уровень активности и работоспособности. Способность жизнестойкости блокировать влияние стрессогенных стимулов позволяет предположить, что она опосредует влияние стереотипной угрозы. В частности, мы предположили:

Гипотеза 3а: чем выше жизнестойкость, тем меньше стереотипная угроза влияет на эффективность решения задач.

Гипотеза 3б: чем выше жизнестойкость, тем меньше стереотипная угроза влияет оценку деятельности.

Для проверки этих предположений было проведено экспериментальное исследование.

\section{Выборка}

В исследовании приняли участие 94 студента I курса факультетов психологии Национального исследовательского университета «Высшая школа экономики» и Российского государственного гуманитарного университета. Среди них 78 женщин и 16 мужчин, возраст - 17-20 лет $(\mathrm{M}=17.62, \mathrm{SD}=0.71)$. 


\section{Процедура исследования}

Исследование проходило в начале учебного года, когда респонденты начали изучать курс статистики в университете. Эксперимент проводился в ходе занятий по математическим методам в психологии и экспериментальной психологии. Преподаватель во время проведения процедуры в аудитории отсутствовал.

В ходе исследования участники были разделены на две группы. Распределение проводилось методом попарного уравнивания. Критерием разделения были баллы, которые респонденты получили при сдаче единого государственного экзамена по математике (ЕГЭ). Для сохранения в тайне цели эксперимента было сказано, что деление на группы необходимо из-за большого количества человек и маленькой вместимости аудиторий.

Независимая переменная. Экспериментальные условия различались отсутствием/наличием стереотипной угрозы. При отсутствии стереотипной угрозы ведущий объяснял респондентам, что цель данного исследования - изучение взаимосвязи между психологическими характеристиками человека и решением математических задач, что это исследование проводится на нескольких факультетах университета, и определял последовательность действий.

При наличии стереотипной угрозы ведущий рассказывал об исследованиях, якобы проведенных для изучения математических способностей у студентов разных специально- стей. По его словам, они показали, что студенты-психологи решают математические задачи гораздо хуже, чем студенты, обучающиеся на других факультетах. После этого ведущий говорил студентам, что цель данного исследования - изучение взаимосвязи между психологическими особенностями и решением математических задач. Это исследование проводится на нескольких факультетах университета. При этом результаты студентов-психологов будут сравниваться с результатами студентов-экономистов, демонстрирующих самые лучшие результаты при выполнении таких заданий. После этого ведущий объяснял студентам последовательность действий.

Зависимые переменные. В ходе эксперимента респонденты решали математические задачи и выражали свое отношение к курсу статистики.

Математические задачи. Респонденты получали 10 математических задач из математической части международного сравнительного исследования качества образования PISA ${ }^{1}$, переведенных на русский язык. При выборе задач учитывалось содержание школьной программы по математике. При этом отличительной особенностью задач PISA является то, что все они вписывают математические знания в контекст реальных проблемных ситуаций, с которыми студент сталкивается в повседневной жизни. Четыре задачи были геометрическими и оценивали представление об окружностях и выпуклых многоугольниках, а также знание и применение теоремы Пифагора, свойств прямоугольного

${ }^{1}$ URL: http://www.oecd.org/pisa 
треугольника, формул площади. Остальные шесть задач были алгебраическими и оценивали умение решать линейные и квадратные уравнения; знание арифметики; умение находить проценты от числа; умение применять и преобразовывать формулы. Все темы содержатся в школьной программе за VIII-IX классы, входят в состав ОГЭ (экзамен, который проводится после IX класса) и ЕГЭ (экзамен, который проводится после XI класса). На решение этих задач студентам отводилось ровно 15 минут. При обработке результатов подсчитывалось число правильно решенных задач.

Отношение $\kappa$ статистике. Для измерения этого параметра использовался опросник Шау (Schau et al., 1995; Schau, 2003), адаптированный для русскоязычной выборки (Орел, Хавенсон, 2013). Он состоит из 34 утверждений, которые респондент должен оценить по 4-балльной шкале от 1 - «совершенно не согласен» до 4 - «совершенно согласен». Эти утверждения образуют шесть шкал:

- «Статистика в профессиональной жизни», например: «Со знанием, полученным в курсах, связанных с математикой и статистикой, мне будет легче найти работу» (прямое утверждение), «Курсы, связанные с математикой и статистикой, бесполезны в моей профессиональной деятельности» (обратное утверждение). Высокий балл по шкале отражает уверенность студента в том, что статистика необходима для решения профессиональных задач.

- «Статистика в повседневной жизни», например: «Я использую математику и статистику в своей повседневной жизни» (прямое утверждение), «Математика и статистика редко встречаются в повседневной жизни» (обратное утверждение). Высокий балл по шкале отражает уверенность студента в том, что статистика необходима в повседневной жизни.

- «Интерес», например: «Я буду получать удовольствие от изучения курсов, связанных с математикой и статистикой», «Мне интересно изучать курсы, связанные с математикой и статистикой» (прямые утверждения). Высокий балл по шкале отражает интерес студента к курсу по статистике.

- «Субъективная легкость», например: «Курсы, связанные с математикой и статистикой, сложны», «Я думаю, что мне придется приложить много стараний при изучении курсов, связанных с математикой и статистикой» (обратные утверждения). Высокий балл по шкале отражает ожидания студента, что курс по статистике будет легким.

• «Ожидания», например: «Я смогу освоить курсы, связанные с математикой и статистикой» (прямое утверждение), «Я совсем не понимаю, что происходит на курсах, связанных с математикой и статистикой» (обратное утверждение). Высокий балл по шкале отражает ожидания студента, что он сможет освоить курс по статистике.

- «Старательность», например: «Я планирую активно работать по ходу курсов, связанных с математикой и статистикой», «Я планирую тщательно готовиться к экзаменам по дисциплинам, связанным с математикой и статистикой» (прямые утверждения). Высокий балл по 
шкале отражает готовность студента вкладываться в изучение курса по статистике.

Модераторы: личностные ресурcы. Для измерения личностных ресурсов респонденты заполняли опросники общей самоэффективности и жизнестойкости.

Самоэффективность. Для измерения этого параметра был использован опросник Р. Шварцера и М. Ерусалема в адаптации В. Ромека. Он состоит из 10 утверждений, которые респондент должен оценить по 4балльной шкале от 1 - «абсолютно не верно» до 4 - «совершенно верно», например: «Если я как следует постараюсь, то всегда найду решение даже сложным проблемам», «Я готов к любым трудностям, поскольку полагаюсь на собственные способности». Высокий балл по этой шкале свидетельствует о высоком уровне самоэффективности.

Жизнестойкость. Для измерения этого параметра был использован опросник жизнестойкости С. Мадди, адаптированный для русскоязычной выборки (Леонтьев, Рассказова, 2006). Он состоит из 45 утверждений, которые респондент должен оценить по 4-балльной шкале: от 1 «скорее нет» до 4 - «скорее да». Эти утверждения образуют три шкалы:

- «Вовлеченность», например: «Я постоянно занят, и мне это нравится» (прямое утверждение), «Мне трудно сближаться с другими людьми» (обратное утверждение). Высокий балл по этой шкале отражает уверенность человека в том, что он может и должен принимать активное участие в происходящих в жизни событиях, может найти то, что является интересным и субъективно значимым;
• «Контроль», например: «Я предпочитаю ставить перед собой труднодостижимые цели и добиваться их» (прямое утверждение), «Я довольно часто откладываю на завтра то, что трудно осуществимо, или то, в чем я не уверен» (обратное утверждение). Высокий балл по этой шкале отражает уверенность человека в том, что борьба и преодоление позволяют повлиять на происходящее, изменить жизнь в желаемую сторону;

- «Принятие риска», например: «Неожиданности дарят мне интерес к жизни» (прямое утверждение), «Мне кажется, если бы в прошлом у меня было меньше разочарований и невзгод, мне было бы сейчас легче жить на свете» (обратное утверждение). Высокий балл по этой шкале отражает уверенность человека в том, что важно действовать даже тогда, когда нет никаких гарантий успеха, поскольку отрицательный результат - тоже полезный опыт.

Чтобы проверить воздействие экспериментальной инструкции, в конце исследования респондентов просили оценить студентов-психологов по 18 биполярным 5-балльным шкалам, отражающим различные психологические особенности и способности. Среди прочего в шкалах оценки присутствовала способность психологов к математике, и именно она являлась ключевой характеристикой, которая учитывалась при обработке результатов.

После завершения исследования был проведен дебрифинг. В ходе него ведущий рассказывал респондентам, что такое стереотипная угроза и как она влияет на эффективность работы. Кроме того, он сообщал об отсутствии 
исследований, говорящих о неспособности психологов к математике, и добавлял, что психологам ничего не мешает освоить курс статистики.

\section{Результаты}

Экспериментальная инструкщия. Для того чтобы определить эффективность экспериментальной инструкции, мы сравнили оценку способности студентов-психологов к математике, которую дали члены разных экспериментальных групп. Результаты показали, что респонденты, работающие в условиях стереотипной угрозы, оценивали математические способности студентов-психологов ниже $(\mathrm{M}=2.67, \mathrm{SD}=1.16)$, чем респонденты, работавшие при отсутствии угрозы $(\mathrm{M}=5.45, \mathrm{SD}=1.13)(t=-11.52$, $p \leqslant 0.000)$. Это означает, что экспериментальная инструкция оказала необходимое воздействие.
Влияние стереотипной угрозы на отношение к статистике. Для проверки гипотез 1а и 16 мы сравнили качество решения математических задач и отношение к статистике у респондентов, работающих при наличии и при отсутствии стереотипной угрозы. Результаты продемонстрировали, что актуализация негативных стереотипов оказала влияние на отношение к статистике (таблица 1). В частности, студенты, работающие при наличии стереотипной угрозы, хуже решали математические задачи $\left(t=9.04^{* *}\right)$, чем студенты, работающие при отсутствии угрозы. Кроме того, они считали статистику менее полезной в повседневной жизни $\left(t=3.10^{* *}\right)$, проявляли меньший интерес к статистике $(t=1.84$, $p \leqslant 0.10-$ на уровне тенденции), считали ее более сложным предметом $\left(t=3.72^{* *}\right)$ и выражали меньшую уверенность в успешном освое-

Таблица 1

Влияние стереотипной угрозы на отношение к статистике

\begin{tabular}{|l|c|c|c|c|c|c|c|}
\hline \multirow{2}{*}{ Шкала } & \multicolumn{2}{|c|}{$\begin{array}{c}\text { Вся } \\
\text { выборка }\end{array}$} & \multicolumn{2}{c|}{$\begin{array}{c}\text { Отсутствие } \\
\text { стереотипной } \\
\text { угрозы }\end{array}$} & \multicolumn{2}{c|}{$\begin{array}{c}\text { Наличие } \\
\text { стереотипной } \\
\text { угрозы }\end{array}$} & Различия \\
\cline { 2 - 8 } & $\mathrm{M}$ & $\mathrm{SD}$ & $\mathrm{M}$ & $\mathrm{SD}$ & $\mathrm{M}$ & $\mathrm{SD}$ & $t$-критерий \\
\hline Количество решенных задач & 5.06 & 1.60 & 5.98 & 1.06 & 3.71 & 1.29 & $9.04^{* * *}$ \\
\hline $\begin{array}{l}\text { Роль статистики } \\
\text { в профессиональной жизни }\end{array}$ & 5.27 & 1.17 & 5.26 & 1.08 & 5.28 & 1.30 & -0.07 \\
\hline $\begin{array}{l}\text { Роль статистики } \\
\text { в повседневной жизни }\end{array}$ & 4.38 & 1.22 & 4.67 & 1.26 & 3.94 & 1.02 & $3.10^{* *}$ \\
\hline Интерес & 4.32 & 1.21 & 4.51 & 1.10 & 4.04 & 1.32 & 1.84 \\
\hline Субъективная легкость & 5.10 & 1.13 & 5.42 & 1.16 & 4.62 & 0.97 & $3.72^{* * *}$ \\
\hline Ожидания & 4.16 & 1.24 & 4.46 & 1.13 & 3.72 & 1.28 & $2.88^{* *}$ \\
\hline Старательность & 5.65 & 1.15 & 5.70 & 1.33 & 5.59 & 0.82 & 0.48 \\
\hline
\end{tabular}

$* * p<0.01, * * * p<0.001$. 
нии этого предмета $\left(t=2.88^{* *}\right)$. В то же время стереотипная угроза не оказала влияния на оценку важности статистики в профессиональной жизни и намерение прикладывать усилия для ее освоения. Таким образом, результаты исследования полностью подтвердили гипотезу 1а и частично - гипотезу 16.

Самоэффективность и жизнестойкость как фактор влияния стереотипной угрозы. Для проверки гипотез 2 и 3 был использован линейный регрессионный анализ. В качестве предикторов рассматривались наличие стереотипной угрозы, психологические ресурсы личности, а также произведение усредненных значений этих показателей. Зависимыми переменными были все параметры оценки статистики и количество правильно решенных задач.

Наиболее важные результаты этого анализа представлены в таблице 2. Они говорят о том, что психологические ресурсы опосредуют влияние стереотипной угрозы на два параметра отношения к статистике: интерес и субъективную легкость. При этом основными модераторами являются самоэффективность и вовлеченность (таблица 2).

С одной стороны, стереотипная угроза оказывает большее влияние на интерес к статистике у людей с высоким уровнем самоэффективности и вовлеченности. В условиях стереотипной угрозы такие люди оценивают статистику как менее интересную,

Таблица 2

Самоэффективность и вовлеченность как модераторы влияния стереотипной угрозы на отношение к статистике

\begin{tabular}{|l|c|c|c|c|c|c|c|}
\hline & \multicolumn{5}{|c|}{ Интерес } & \multicolumn{3}{c|}{ Легкость } \\
\hline & Шаг 1 $(\beta)$ & Шаг 2 $(\beta)$ & Шаг 3 $(\beta)$ & Шаг 1 $(\beta)$ & Шаг 2 $(\beta)$ & Шаг 3 $\beta)$ \\
\hline \multicolumn{7}{|c|}{ Самоэффективность } \\
\hline Стереотипная угроза & $-0.297^{* *}$ & -0.082 & -0.111 & $-0.353^{* * *}$ & $-0.405^{* * *}$ & $-0.349^{* * *}$ \\
\hline Самоэффективность & & $0.608^{* * *}$ & $0.804^{* * *}$ & & -0.147 & $-0.528^{* * *}$ \\
\hline $\begin{array}{l}\text { Стереотипная угроза } \\
\text { Самоэффективнсть }\end{array}$ & & & $-0.300^{* *}$ & & & $0.582^{* * *}$ \\
\hline$R^{2}$ с поправкой & 0.078 & 0.398 & 0.440 & 0.115 & 0.125 & 0.296 \\
\hline$R^{2}$ на шаге & 0.088 & 0.324 & 0.046 & 0.125 & 0.019 & 0.175 \\
\hline & & Вовлеченность & & \\
\hline Стереотипная угроза & $-0.297^{* *}$ & -0.130 & $-0.182^{*}$ & $-0.353^{* * *}$ & $-0.456^{* * *}$ & $-0.404^{* * *}$ \\
\hline Вовлеченность & & $0.599^{*}$ & $0.772^{* * *}$ & & $-0.371^{* * *}$ & $-0.546^{* * *}$ \\
\hline $\begin{array}{l}\text { Стереотипная угроза } \times \\
\text { Вовлеченность }\end{array}$ & & & $-0.326^{* * *}$ & & & $0.329^{* *}$ \\
\hline$R^{2}$ с поправкой & 0.078 & 0.406 & 0.470 & 0.115 & 0.235 & 0.299 \\
\hline$R^{2}$ на шаге & 0.088 & 0.331 & 0.069 & 0.125 & 0.127 & 0.070 \\
\hline
\end{tabular}


чем при отсутствии стереотипной угрозы. В то же время у людей с низким уровнем самоэффективности и вовлеченности не наблюдается подобных различий.

С другой стороны, стереотипная угроза оказывает большее влияние на оценку сложности статистики у людей с низким уровнем самоэффективности и вовлеченности. В условиях стереотипной угрозы такие люди оценивают статистику как более сложную, чем при отсутствии стереотипной угрозы. В то же время у людей с высоким уровнем самоэффективности и вовлеченности не наблюдается подобных различий.

В целом эти результаты опровергают гипотезы $2 \mathrm{a}$ и За. В то же время они частично подтверждают гипотеза 2б и $3 б$.

\section{Обсуждение результатов}

Владение статистическими методами обработки данных необходимо психологу как в фундаментальных, так и в прикладных исследованиях. Тем не менее теория вероятностей, математическая статистика и методы анализа данных относятся к числу самых трудных предметов для начинающих психологов. Объясняя свое нежелание заниматься статистикой, студенты часто говорят о том, что психологи - это гуманитарии, которые неспособны к математике. Подобные представления порождают стереотипную угрозу, которая оказывает влияние как на отношение к предмету, так и на решение математических задач.

В частности, результаты нашего исследования показали, что стереотипная угроза оказывает как кратко- временное, так и долговременное воздействие на студентов-психологов. Студенты, работающие в условиях стереотипной угрозы, хуже решали математические задачи, чем те, кто работал при отсутствии угрозы (кратковременное воздействие). Интересно, что стереотипная угроза оказала воздействие даже на психологов-первокурсников, которые лишь недавно попали в профессиональное сообщество и, скорее всего, не обладают устойчивыми профессиональными стереотипами. Тем не менее можно предположить, что сформированность стереотипов оказывает влияние на стабильность воздействия угрозы. На людей со слабо сформированными стереотипами она оказывает влияние лишь в отдельных случаях, тогда как на людей с хорошо сформированными стереотипами она влияет постоянно.

Помимо этого, студенты, работающие в условиях стереотипной угрозы, считали статистику менее важной в повседневной жизни, проявляли к ней меньший интерес, считали ее более сложной и меньше верили в возможность освоения статистических методов анализа (долговременное воздействие). Иными словами, стереотипная угроза создавала долговременные барьеры на пути освоения статистики, благодаря уменьшению математической самоэффективности студентов и деидентификации с областью деятельности. Этот вывод соответствует результатам ранее проведенных исследований, продемонстрировавших позитивную связь между положительным отношением к курсу статистики и успеваемостью по дисциплинам, имеющим отношение к математике и 
методологии проведения исследования (Lalonde, Gardner, 1993; Onwuegbuzie, 2000; Onwuegbuzie, Seaman, 1995; Onwuegbuzie, Wilson, 2003; Zanakis, Valenza, 1997; Zeidner, 1990).

В то же время стереотипная угроза не оказала влияния на оценку важности статистики в профессиональной деятельности и готовности прикладывать усилия для ее освоения. Можно предположить, что этот результат связан с российской спецификой образования студентовпсихологов. Математические дисциплины преподаются на младших курсах и являются обязательными для изучения: чтобы продолжить обучение, студенты должны сдать этот предмет на положительную оценку. К тому же во время курса преподаватели неоднократно подчеркивают, что статистика играет важную роль при обработке результатов психологических исследований. Таким образом, оценка важности статистики в профессиональной жизни и необходимость усилий для ее освоения задаются извне. Как следствие, эти параметры слабо зависят от психологического состояния и уровня достижений студента.

Интересно, что влияние стереотипной угрозы опосредуется личностными ресурсами человека самоэффективностью и жизнестойкостью. Однако воздействие этих характеристик имеет несколько ограничений. Во-первых, они играют роль посредников, когда речь идет об отношении к области деятельности, но не о решении задач здесь и сейчас. Иными словами, они усиливают или ослабляют долговременные, но не кратковременные последствия актуализации стереотипов, сказывают- ся на будущих, но не на текущих достижениях. В нашем исследовании они опосредовали воздействие стереотипной угрозы на интерес к деятельности.

Во-вторых, эту роль играют не все параметры жизнестойкости. В данном случае наибольшую роль играла вовлеченность - уверенность человека в том, что он может и должен принимать активное участие в происходящих в жизни событиях, может найти то, что является интересным и субъективно значимым. Возможно, это произошло, поскольку именно вовлеченность тесно связана с интересом человека к деятельности и готовностью прикладывать усилия для ее реализации.

И наконец, в-третьих, роль личностных ресурсов зависит от параметра оценки деятельности. В нашем исследовании высокая самоэффективность и вовлеченность уменьшали воздействие стереотипной угрозы на оценку субъективной сложности статистических задач. Иными словами, благодаря высокой самоэффективности и вовлеченности студенты, столкнувшиеся со стереотипной угрозой, воспринимали статистические задачи как такие же простые, как и те, кто не столкнулся со стереотипами. В этом случае самоэффективность и вовлеченность действительно играли роль характеристик, позволяющих студентам успешно справиться с трудной ситуацией.

В то же время самоэффективность и вовлеченность оказывали противоположное воздействие на связь между стереотипной угрозой и интересом к статистике. Влиянию стереотипной угрозы оказались менее подвержены люди с низкой 
самоэффективностью и вовлеченностью. Именно они, столкнувшись со стереотипной угрозой, демонстрировали такой же интерес к статистике, как и студенты, не подвергавшиеся воздействию стереотипов. Тогда как люди с высокой самоэффективностью и вовлеченностью демонстрировали меньший интерес к этому предмету.

С чем может быть связано подобное воздействие личностных ресурсов? Возможно, что в данном случае речь идет о своеобразной психологической защите. Люди, верящие в свои силы и вовлеченные в происходящее, отказываются признать свою неспособность справиться с задачей, и поэтому одинаково оценивают ее сложность вне зависимости от актуализации стереотипов. В то же время они компенсируют возможные неудачи, заявив об отсутствии интереса к заведомо сложной деятельности.

В целом полученные результаты расширяют наше представление о влиянии стереотипной угрозы. Во-пер- вых, они демонстрируют, что стереотипную угрозу могут порождать не только широко распространенные гендерные, этнические и возрастные представления, но также и узконаправленные профессиональные стереотипы. Во-вторых, они свидетельствуют о том, что стереотипная угроза оказывает разное влияние на разные параметры отношения к деятельности. В частности, она оказывает наибольшее воздействие на оценку тех параметров, которые не обсуждаются публично: в этом случае оценка определяется только личными предпочтениями человека, но не ожиданиями окружающих. И наконец, в-третьих, они показывают, что личные характеристики человека, такие как самоэффективность и жизнестойкость, могут блокировать воздействие стереотипной угрозы. Однако их влияние противоречиво и ярче проявляется, когда речь идет о долговременных последствиях, связанных с изменением оценки деятельности, а не о текущих достижениях члена стереотипизированной группы.

\section{Литература}

Гордеева, Т. О. (2011). Самоэффективность как составляющая личностного потенциала. В кн. Д. А. Леонтьев (ред.), Личностный потенциал: структура и диагностика (с. 241-266). М.: Смысл.

Леонтьев, Д. А., Рассказова, Е. И. (2006). Тест жизнестойкости. М.: Смысл.

Орел, Е. А., \& Хавенсон, Т. Е. (2013). Отношение к статистике у студентов, изучающих социальные науки: операционализация понятия и его измерение. Психология. Журнал Высшей школь әкономики, 10(1), 37-54.

Осин, Е. Н., \& Рассказова, Е. И. (2013). Краткая версия теста жизнестойкости: психометрические характеристики и применение в организационном контексте. Вестник Московского университета. Серия 14. Психология, 2, 147-165.

Рассказова, Е. И., \& Леонтьев, Д. А (2011). Жизнестойкость как составляющая личностного потенциала. В кн. Д. А. Леонтьев (ред.), Личностный потенциал: структура и диагностика (с. 178-209). М.: Смысл.

Ссылки на зарубежные источники см. в разделе References после англоязычного блока. 


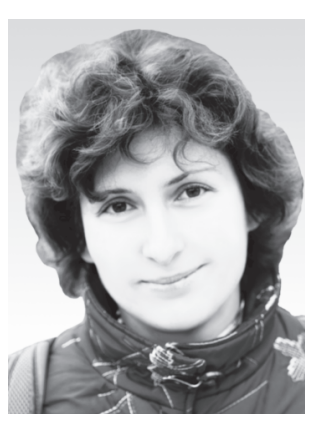

Гулевич Ольга Александровна - профессор, департамент психологии; ведущий научный сотрудник, лаборатория экспериментальной и поведенческой экономики, Национальный исследовательский университет «Высшая школа экономики», доктор психологических наук.

Сфера научных интересов: психология межгрупповых отношений, психология политического протеста, психология массовой коммуникации.

Контакты: ogulevich@hse.ru

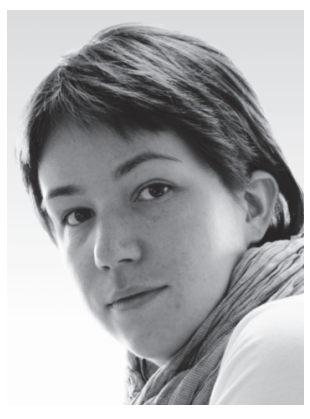

Орел Екатерина Алексеевна - научный сотрудник, Центр мониторинга качества образования Института образования, Национальный исследовательский университет «Высшая школа экономики», кандидат психологических наук.

Сфера научных интересов: измерение в социальных науках, оценка компетенции взрослых, методы психологического исследования, ключевые профессиональные компетенции, высшее образование.

Контакты: eorel@hse.ru

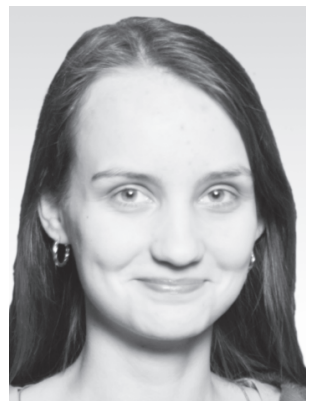

Бурова Маргарита Борисовна - выпускница бакалавриата, департамент психологии, факультет социальных наук, Национальный исследовательский университет «Высшая школа экономики».

Сфера научных интересов: высшее образование, математические методы в психологии, статистический анализ.

Контакты: mbburova@gmail.com

\title{
Why Psychologists Don't Know Math? The Influence of Actualization of Professional Stereotypes on Solving Math Problems
}

\author{
Olga A. Gulevich ${ }^{\mathrm{a}}$, Ekaterina A. Orel ${ }^{\mathrm{a}}$, Margarita B. Burova ${ }^{\mathrm{a}}$
}

${ }^{a}$ National Research University Higher School of Economics, 20 Myasnitskaya Str., Moscow, 101000, Russian Federation

\begin{abstract}
Stereotype threat is an important factor influencing educational and professional achievements. Stereotypes are the origin of this threat that emphasize the inability of members of a social group to solve specific problems. In this study we analyzed the influence of stereotypes about psychologists ("Psychologists are not good at math") on the attitudes of students-psychologists
\end{abstract}


to a statistics course and the quality of their solutions of mathematical tasks. We have suggested that the actualization of the students' stereotype threat could worsen their attitudes to the statistics course and reduce the quality of solutions of mathematical tasks. However, this influence depends on the personal resources possessed by students: a person with higher self-efficacy and resilience (hardiness) could be less exposed to negative stereotypes. The study involved 94 psychology students , who had recently started a study of statistics. Members of one experimental group were exposed to a stereotype threat, and the other group was not. We actualized the negative stereotypes of the members of the first group: they were told that according to different studies psychologists solve mathematical problems worse than people of other professions. At the same time we didn't actualize the stereotype threat for the members of the second group. After that, all participants filled in the questionnaire for measuring self-efficacy, resilience, attitude toward statistics and solved some math tasks. According to the hypothesis, the study results showed that the stereotype threat actually reduces the efficiency of solution of mathematical tasks and worsens the attitudes to statistics. However, this influence is mediated by self-efficacy, and by one component of resilience - commitment.

Keywords: stereotypes, stereotype threat, attitude toward statistics.

\section{References}

Appel, M., Kronberger, N., \& Aronson, J. (2011). Stereotype threat impairs ability building: effects on test preparation among women in science and technology. European Journal of Social Psychology, 41, 904-913.

Boucher, K. L., Rydell, R. J., Van Loo, K. J., \& Rydell, M. T. (2012). Reducing stereotype threat in order to facilitate learning. European Journal of Social Psychology, 42, 174-179.

Cadinu, M., Maass, A., Frigerio, S., Impagliazzo, L., \& Latinotti, S. (2003). Stereotype threat: the effect of expectancy on performance. European Journal of Social Psychology, 33, 267-285.

Cadinu, M., Maass, A., Lombardo, M., \& Frigerio, S. (2006). Stereotype threat: the moderating role of locus of control beliefs. European Journal of Social Psychology, 36, 183-197.

Croizet, J.-C., Desprus, G., Gauzins, M.-E., Huguet, P., Leyens, J.-P., \& Meat, A. (2004). Stereotype threat undermines intellectual performance by triggering a disruptive mental load. Personality and Social Psychology Bulletin, 30, 721-731.

Davies, P. G., Spencer, S. J., \& Steele, C. M. (2005). Clearing the air: identity safety moderates the effects of stereotype threat on women's leadership aspirations. Journal of Personality and Social Psychology, 88, 276-287.

Desrichard, O., \& Kopetz, C. (2005). A threat in the elder: the impact of task-instructions, self-efficacy and performance expectations on memory performance in the elderly. European Journal of Social Psychology, 35, 537-552.

Ford, T. E., Ferguson, M. A., Brooks, J. L., \& Hagadone, K. M. (2004). Coping sense of humor reduces effects of stereotype threat on women's math performance. Personality and Social Psychology Bulletin, 30, 643-653.

Good, C., Rattan, A., \& Dweck, C. S. (2012). Why do women opt out? Sense of belonging and women's representation in mathematics. Journal of Personality and Social Psychology, 102, 700-717. 
Gordeeva, T. O. (2011). Samoeffektivnost' kak sostavlyayushchaya lichnostnogo potentsiala [Self-efficiency as a component of personality potential]. In D. A. Leontiev (Ed.), Lichnostnyi potentsial: struktura i diagnostika [Personality potential: Structure and diagnostics] (pp. 241-266). Moscow: Smysl.

Grimm, L. R., Markman, A. B., Maddox, W. T., \& Baldwin, G. C. (2009). Stereotype threat reinterpreted as a regulatory mismatch. Journal of Personality and Social Psychology, 96, 288-304.

Johns, M., Inzlicht, M., \& Schmader, T. (2008). Stereotype threat and executive resource depletion: examining the influence of emotion regulation. Journal of Experimental Psychology: General, 137, 691-705.

Keller, J., \& Dauenheimer, D. (2003). Stereotype threat in the classroom: dejection mediates the disrupting threat effect on women's math performance. Personality and Social Psychology Bulletin, 29, 371-381.

Klein, O., Pohl, S., \& Ndagijimana, C. (2007). The influence of intergroup comparisons on Africans' intelligence test performance in a job selection context. Journal of Psychology, 141, 453-467.

Lalonde, R. N., \& Gardner, R. C. (1993). Statistics as a Second Language? A Model for Predicting Performance in Psychology Students. Canadian Journal of Behavioural Science, 25, 108-125.

Leitner, J. B., Jones, J. M., \& Hehman, E. (2013). Succeeding in the face of stereotype threat: the adaptive role of engagement regulation. Personality and Social Psychology Bulletin, 39, 17-27.

Leontiev, D. A., \& Rasskazova, E. I. (2006). Test zhiznestoikosti [Hardiness test]. Moscow: Smysl.

Maass, A., \& Cadinu, M. (2003). Stereotype threat: When minority members underperform. European Review of Social Psychology, 14, 243-275.

Maass, A., D'Ettole, C., \& Cadinu, M. (2008). Checkmate? The role of gender stereotypes in the ultimate intellectual sport. European Journal of Social Psychology, 38, 231-245.

Maddi, S. R. (1987). Hardiness training at Illinois Bell Telephone. In J. P. Opatz (Ed.), Health promotion evaluation (pp. 101-115). Stevens Point, WI: National Wellness Institute.

Maddi, S. (1998). Dispositional hardiness in health and effectiveness. In H. S. Friedman (Ed.), Encyclopedia of mental health (pp. 323-335). San Diego, CA: Academic Press.

Maddi, S., Kahn, S., \& Maddi, K. (1998). The effectiveness of hardiness training. Consulting Psychology Journal: Practice and Research, 50, 78-86.

Marx, D. M., \& Roman, J. S. (2002). Female role models: protecting women's math test performance. Personality and Social Psychology Bulletin, 28, 1183-1193.

Marx, D. M., \& Stapel, D. A. (2006). It's all in the timing: measuring emotional reactions to stereotype threat before and after taking a test. European Journal of Social Psychology, 36, 687-698.

Muzzatti, B., \& Agnoli, F. (2007). Gender and mathematics: attitudes and stereotype threat susceptibility in Italian children. Developmental Psychology, 43, 747-759.

O'Brien, L. T., \& Crandall, C. S. (2003). Stereotype threat and arousal: effects on women's math performance. Personality and Social Psychology Bulletin, 29, 782-789.

Onwuegbuzie, A. J. (2000). Attitudes toward Statistics Assessments. Assessment and Evaluation in Higher Education, 25, 321-339.

Onwuegbuzie, A. J., \& Seaman, M. A. (1995). The effect on time constraints and statistics test anxiety on test performance in a statistics course. The Journal of Experimental Education, 63, 115-124.

Onwuegbuzie, A. J., \& Wilson, V. A. (2003). Statistics anxiety: nature, etiology, antecedents, effects, and treatments - a comprehensive review of the literature. Teaching in Higher Education, 8, 195-209.

Orel, E. A., \& Khavenson, T. E. (2013). Attitudes towards statistics in social science students: Operationalization and measurement. Psychology. Journal of Higher School of Economics, 10(1), 37-54. (in Russian) 
Osin, E. N., \& Rasskazova, E. I. (2013). A short version of the Hardiness Test: Psychometric properties and organizational application. Vestnik Moskozskogo Universiteta. Seriya 14. Psikhologiya, 2, 147-165. (in Russian)

Rasskazova, E. I., \& Leontiev, D. A (2011). Zhiznestoikost' kak sostavlyayushchaya lichnostnogo potentsiala. [Hardiness as a component of personality potential]. In D. A. Leontiev (Ed.), Lichnostnyi potentsial: struktura i diagnostika [Personality potential: Structure and diagnostics] (pp. 178-209). Moscow: Smysl.

Rothgerber, H., \& Wolsiefer, K. (2014). A naturalistic study of stereotype threat in young female chess players. Group Processes and Intergroup Relations, 17, 79-90.

Rydell, R. J., Rydell, M. T., \& Boucher, K. L. (2010). The effect of negative performance stereotypes on learning. Journal of Personality and Social Psychology, 99, 883-896.

Schau, C. (2003, August). Students' attitudes: the "other" important outcome in statistics education. Paper presented at the Joint Statistics Meetings, San Francisco. Retrieved from http://evaluationandstatistics.com/JSM2003.pdf

Schau, C., Stevens, J., Dauphinee, T., \& Del Vecchio, A. (1995). The development and validation of the survey of attitudes toward statistics. Educational and Psychological Measurement, 55, 868-875.

Schmader, T., \& Johns, M. (2003). Converging evidence that stereotype threat reduces working memory capacity. Journal of Personality and Social Psychology, 85, 430-452.

Schmader, T., Johns, M., \& Forbes, C. (2008). An integrated process model of stereotype threat effects on performance. Psychological Review, 115, 336-356.

Stone, J. (2002). Battling doubt by avoiding practice: the effects of stereotype threat on self-handicapping in White athletes. Personality and Social Psychology Bulletin, 28, 1667-1678.

Van Loo, K. J., \& Rydell, R. J. (2013). On the experience of feeling powerful: perceived power moderates the effect of stereotype threat on women's math performance. Personality and Social Psychology Bulletin, 39, 387-400.

Zanakis, S. H., \& Valenza, E. R. (1997). Student anxiety and attitudes in business statistics. Journal of Education for Business, 72, 10-16.

Zeidner, M. (1990). Does test anxiety bias scholastic aptitude test performance by gender and sociocultural group. Journal of Personality Assessment, 55, 145-160.

Olga A. Gulevich - professor, Department of Psychology; leading research fellow, Laboratory for Experimental and Behavioural Economics, National Research University Higher School of Economics, D.Sc.

Research area: psychology of intergroup relations, psychology of political protest, psychology of mass communication.

E-mail: ogulevich@hse.ru

Ekaterina A. Orel - research fellow, Institute of Education, Center of Education Quality Monitoring, National Research University Higher School of Economics, Ph.D.

Research area: measurement in the social sciences, evaluation of the competence of adults, methods of psychological research, key professional competences, higher education.

E-mail: eorel@hse.ru

Margarita B. Burova - bachelor of psychology, School of Psychology, Faculty of Social Sciences, National Research University Higher School of Economics.

Research area: higher education, mathematical methods in psychology, statistical analysis.

Email: mbburova@gmail.com 